\title{
What Does the Public Think about Sex Offender Registers? Findings From a National
}

\section{Australian Study}

Professor Lorana Bartels, Criminology Program Leader, Australian National University;

Adjunct Professor, University of Canberra and University of Tasmania

Corresponding author: lorana.bartels@anu.edu.au

Dr Karen Gelb, University of Melbourne

Dr Caroline Spiranovic, Senior Lecturer, University of Tasmania

Emeritus Professor Kate Warner AC, University of Tasmania

Dr Lynne Roberts, Curtin University

Associate Professor Julia Davis, University of South Australia

This article presents data from questions about sex offender registration orders in a large national survey on Australian public opinion about adult sex offenders. It outlines the legislative frameworks that govern these registers in Australia and discusses the use of public registers, the research on the effectiveness of sex offender registers and Australian attitudes to such registers. Our surveys of three cohorts of members of the Australian public reveal strong public support for sex offender registers, especially for cases involving child victims. However, there was also support for judicial discretion in the imposition of orders and reduced support for automatic registration where a non-custodial sentence is imposed. The Australian Government has recently announced the establishment of a national public sex offender register, but our findings show limited support for this approach. The implications for policy and practice are considered.

Keywords: Australia; jurors; sentencing; public opinion; sex offender registers 


\section{Introduction}

As Bartels et al. have noted, '[f] ew categories of offender invoke as strong a response from politicians and the community as sex offenders' $(2019$, p. 41$)$. One of the ways that governments in Australia and overseas have sought to respond to this issue is by introducing sex offender registers, which seek to provide a means of monitoring offenders' post-sentence behaviour in the community to prevent further offences and to facilitate investigations of any new crimes committed (Vess, et al., 2011).

While there is a substantial body of research from the United States (US) on community views on sex offender registers, there is scant literature on the views of Australians. This represents a significant gap; one of the oft-touted justifications for such registers is that they can make the community feel safer. This article aims to address this gap by presenting data from a national survey on Australian public opinion about sex offenders. In particular, the discussion examines public opinion on a range of issues relevant to sex offender registration orders (SOROs).

\section{Background}

\section{Legislative Frameworks in Australia}

Sex offender registration laws were introduced in each Australian state and territory between 2000 and 2006 (for background, see Vess et al., 2011). As set out in Table 1, most of the registers (Australian Capital Territory (ACT), New South Wales (NSW), Northern Territory (NT), Queensland (Qld) and South Australia (SA)) are specifically focused on child sex offenders, while Tasmania (Tas), Victoria (Vic) and Western Australia (WA) are broader in scope.

The requirements vary across jurisdictions (eg, as to relevant offences, age of victims and provisions for juvenile offenders), but all require registered offenders in the community to inform police of their location and other personal details (for example, change of address, name, employment details, car registration and internet service provider). In a recent analysis of legislative reforms dealing with the post-sentence management of sex offenders, Bartels et al. (2019) found that the scope of Australia's sex offender registers had been extended in several ways, including increases in the number of registrable offences, a widening of the circumstances in which offenders must be registered, inclusion of offenders registered in another jurisdiction, additional police powers in relation to registered offenders (eg, taking DNA samples) and the imposition of more restrictive conditions.

\section{[insert Table 1 about here]}

In all jurisdictions, reporting requirements apply to 'Class 1' and 'Class 2' offences. Some create additional categories (eg, Sex Offenders Registration Act 2005 (Vic) s 8, which creates Class 3 and Class 4 offences, involving adult victims). The offence category determines the length of the reporting period. For example, under the Child Protection (Offenders

Registration) Act 2000 (NSW), a registrable offender convicted of a single 'Class 2 offence', 
which includes 'an offence that involves sexual touching or a sexual act against or in respect of a child...punishable by imprisonment for 12 months or more', as well as non-sexual offences involving child victims, such as manslaughter or grievous bodily harm (s 3 ), is subject to reporting requirements for eight years (s 14A(1)(a)). A 'Class 1 offence', which includes child murder and sexual intercourse with a child, attracts a registration period of 15 years (s 14A(1)(b)). Under s 14A(1)(c), this is extended to life registration for:

- Class 1 offenders who subsequently commit and are found guilty of another registrable offence; and

- Class 2 offenders who subsequently commit and are found guilty of:

- a Class 1 offence;

○ two or more Class 2 offences; or

o three or more such offences in total.

There is general consistency across jurisdictions in the length of reporting period for specified offence categories and uniformity in relation to reporting and register procedures (Vess et al., 2011).

Registration is generally mandatory, subject to the offence type and/or the number of offences committed, although courts in Tasmania retain a discretion not to make the order if 'satisfied that the person does not pose a risk of committing a reportable offence in the future' (Community Protection (Offender Reporting) Act 2005 (Tas) s 6). In Victoria, the Act automatically applies to all adults sentenced for committing Class 1 or Class 2 sexual offences against a child (Sex Offenders Registration Act 2004 (Vic) s 6(4)). Further, under s 11(1), courts may impose an order on adult offenders sentenced for sexual offences that are not Class 1 or 2 offences (including Class 3 and 4 offences), if satisfied that they 'pose a risk to the sexual safety of one or more persons in the community' (s 11(3)).

As set out in Table 1, most jurisdictions provide exceptions for specified sentencing outcomes. In NSW, the exception is limited to cases involving a dismissal (for Class 1 and 2 offences), while Queensland, SA, the ACT and the NT exempt cases where the offender was sentenced for a single Class 2 offence (in Qld, SA and the ACT) or a prescribed offence (in NT) which does not include a prison term or supervision requirement. In the ACT, the exception also applies where the court makes a non-conviction order for both Class 1 and 2 offences. By contrast, the legislation in Tasmania, Victoria and WA does not provide any exceptions on the basis of sentence type.

\section{Public Sex Offender Registers}

In the US, information on the name, appearance and location of high-risk sex offenders has been available to the public for over 25 years. According to Hall (2019), the only other countries that allow public access to this information are South Korea and the Maldives, although these appear to be narrower in both scope and use than the US model (see 
respectively Kim, 2019; Malsa, 2020). A more limited form of public disclosure has also been available in the United Kingdom since 2010 (Napier et al., 2018).

WA is currently the only jurisdiction in Australia that allows members of the public to have access to certain details about people on the register, in limited circumstances. Since 2012, residents who enter their name and driver's licence can request information on registered sex offenders living in their area. Parents may also submit a request as to whether an individual who has contact with their child is a registered offender (Napier et al., 2018). In the first nine months of operation, the register was reportedly accessed about 100,000 times (Taylor, 2017).

In January 2019, Home Affairs Minister Peter Dutton announced the Federal Government's intention to introduce a national public child sex offender register, which would reportedly have a 'strong deterrent effect on offenders and ensure that parents are not in the dark about whether a registered sex offender has access to their children' (Sakzewski, 2019, np). He was reported to have written to the states and territories, urging them to support his proposal for a national database. The move received a range of responses, from strong support to opposition (see Conifer, 2019; Harris \& McPhaedran, 2018; Law Council of Australia, 2019.

Australia currently has a non-public National Child Offender System. This includes the Australian National Child Offender Register, which permits authorised police officers to register, manage and share information about registered offenders, in order to reduce offenders' likelihood of reoffending (Australian Criminal Intelligence Commission 2020). Importantly, it is not intended to be punitive.

Despite the criticism of its proposal and the existing measures to manage sex offenders in the community, in April 2019, the Australian Government (2019) allocated \$7.8 million to establish a national public child sex offender register. The proposed register will include information on sex offenders' names, aliases, photographs, date of birth, physical description, general location and the nature of their offending. Hetty Johnson described the decision as a waste of money and suggested there was no research indicating this would protect children (cited in Layt, 2019).

\section{The Effectiveness of Sex Offender Registers}

There is an established body of US research on the effectiveness of sex offender registration and notification (SORN) regimes (for an overview, see Cubellis et al., 2018; Harris et al., 2018). Specifically, research has shown that public sex offender registers are generally not effective at protecting the community and may even increase the risk of reoffending (see Cui et al., 2018). Freeman (2012) found that SORN attaches substantial stigma to offenders and reduces their ability to reintegrate successfully, leading to higher recidivism rates for these offenders than for those who had committed their offences before the commencement of the relevant legislation and were not subject to these laws. In addition, by treating all sex offenders alike, such schemes widen the net of sex offenders under monitoring and reporting requirements. This, in turn, may compromise the capacity of registration and notification systems to distinguish between offenders who pose a substantial versus minimal risk, thus 
diverting attention and resources away from the management of genuinely high-risk offenders (Harris, et al., 2010; for comment on the issues with risk prediction more generally, see eg McKay, 2020). On the basis of a large body of US research, Letourneau et al. (2010) found there was increasing evidence that SORN is ineffective for managing sex offenders in the community and argued that broad notification presents all offenders as dangerous, rather than focusing the public on those offenders presenting the biggest threat to the communit. This is supported by Prescott and Rockoff (2011), who separately analysed the effects of registration and public notification and found that the former appeared to reduce recidivism, but public notification did not.

Research by the Australian Institute of Criminology considered the extent to which public and non-public sex offender registers reduce sexual (re)offending and influence community perceptions of safety. Drawing principally on research from the US, Napier et al. found that, while public registers are supported by the public, there is little evidence of an impact on community fear levels or recidivism, beyond a small deterrent effect for first-time offenders.

\section{Australian Research on Attitudes to Sex Offender Registers}

The comment by Napier et al. that registers have strong public support is somewhat curious, given they also acknowledged that there were almost no empirical studies on attitudes to an Australian public register $(2018$, p. 8). Napier et al. referred to the only published Australian study we are aware of that has focused on community attitudes towards public sex offender registers: Taylor's (2017) web-based survey of 162 users of WA's online public sexual offender register ( $83 \%$ of whom were based in Western Australia, with most of the remaining respondents based in Victoria). This revealed that $67 \%$ of respondents supported an Australia-wide online public register; $67 \%$ felt that the public had a right to know if convicted child sexual offenders were living in the area; and 56\% felt the community had a right to know the identity of all convicted child sexual offenders. Paradoxically, however, respondents were not confident that this would prevent child sexual abuse (14\%), while $23 \%$ thought it would help with police detection and $32 \%$ felt it would protect children from registered sex offenders. There were also concerns that the register stigmatises offenders and/or makes it difficult for them to reintegrate. The fact that the level of confidence in sex offender registers is mixed is especially surprising, given the likely biased nature of the sample, namely, people who had accessed the WA sex offender register. In an unpublished paper based on interviews with 64 members of the public about their knowledge and use of the WA register, Gateley and Carpenter (2019) found that most participants were unaware of it and had not accessed it, but, once aware of it, believed they had the right to have access to this information. Participants who had accessed the website found that the information available was limited and that they had expected more personal and geographical details. Furthermore, despite warnings about the privacy of information on the website, participants indicated they would share their knowledge with others, if aware of an offender in their area. The authors suggested that these findings raise issues about whether public registers hinder rehabilitation and are the best use of funding and resources for community protection. 
The only other relevant Australian public opinion study was conducted by Shackley et al. (2013), who surveyed 552 adults identified through social media sites. Their hypothesis was that people who are more supportive of sex offender management policies, including sex offender registration and community notification, would have more negative attitudes towards sex offenders than those who are less supportive of these policies. Their findings did not support this hypothesis; in explaining these findings, Shackley et al. (2013) suggested that this might be because the item used to measure support implied public perceptions of sex offenders as a homogenous group with the same management needs.

For completeness, we note here the Australian studies with professionals who work with sex offenders and/or administer offender registers. In 2014, a study of 24 police personnel involved with the operation of sex offender registers in three unnamed jurisdictions found that respondents did not support a public register and perceived this as a political strategy in response to public fear (Powell et al., 2014). Specifically, respondents expressed concern about offenders being publicly ostracised and denied social support, potentially increasing pressure and the risk of re-offending. They were also concerned about the additional burden on police resources and the potential reduction in offenders' compliance with updating personal details and family members' reporting of new offences, due to fear of social stigma. Public registers were also thought to divert public perception away from the 'real' issue, namely that sexual offences are generally committed by someone known to the victim and the importance of parental protection and supervision in preventing child sexual abuse. A more recent study with 17 relevant police officers across Australia (Masters \& Kebbell, 2019) found that some were worried about the community's high expectations and that police would be unlikely to meet these expectations (this aligns with findings in the US context by Harris et al., 2018). Although all of Masters and Kebbell's participants felt that having a register was better than not having a register, the authors also identified the need for the public to be better informed about how the register works, to facilitate more realistic expectations of the police.

The WA regime has also been the subject of specific research on the views of relevant professionals. Day et al. conducted interviews with professionals who work with sex offenders in the community in WA. They found broad support for non-public registration schemes, but expressed concern that the then-planned WA model would be 'counterrehabilitative' (2014, p. 182). Whitting et al.'s (2016) interviews with 21 specialist police officers responsible for the registration and monitoring of sex offenders in the community and for managing the WA community notification scheme are also instructive. They found mixed views on whether a public register would increase public safety; some felt it might increase perceptions of safety, while others were concerned it might create a false sense of security. In follow-up research, Whitting et al. (2017) interviewed 18 police officers and analysed quantitative and qualitative police data. They found no consistent view that the WA register had significantly increased police workloads, led to vigilantism, impacted adversely on offenders' psychological well-being or resulted in their non-compliance with reporting obligations. On the other hand, their results 
also do not provide compelling evidence that it has had any observable positive effects. In light of this and the evident costs involved - both fiscal and human - in implementing such schemes, it would perhaps be prudent for other jurisdictions to consider carefully their overall benefits before proceeding further (2017, p. 353).

Some of the concerns expressed by law enforcement in Australia about the potential implications of public registers are borne out by the US experience. Harris et al. (2018) found that the 105 law enforcement representatives in their study considered SORN to be most effective in relation to inter-agency information-sharing and monitoring offenders, moderately effective in respect of informing the public and supporting investigations, and less effective in terms of reducing the likelihood of re-offending. In a linked study by Cubellis et al. (2018), the same 105 law enforcement representatives acknowledged the collateral consequences of SORN, including workload and stigma for registered offenders, but nevertheless supported the model. In addition, Cubellis et al. found that larger registries resulted in greater collateral impacts for registered offenders (eg, difficulties with housing and employment), which has implications for Australia's proposed national model.

Finally, we note Seidler's (2010) research with eight registered offenders in NSW. This revealed that these offenders perceived the register as an investigative tool to help the police, rather than helping to reduce their offending, while some thought it might adversely impact their relationship with the police. They also perceived the register as an extension of their punishment and considered the requirements to be unfair. Some participants also felt that registration might increase their risk of re-offending and/or that it was neutral or even unhelpful in terms of managing their risk, as it did not offer them any support services.

This literature review shows that although there is some research on how professionals and registered offenders perceive sex offender registers, there is a significant gap in our understanding of public attitudes to such registers in Australia. This article attempts to fill that gap by presenting findings from a survey of participants in the National Jury Sentencing Study.

\section{Method}

The method for this study is described in more detail in Spiranovic et al. (in preparation) and largely replicates the approach adopted in the Tasmanian Jury Study (Warner \& Davis, 2012) and the Victorian Jury Study (Warner, et al., 2017). ${ }^{1}$ The present study was part of a large mixed-methods, four-stage national study on jurors' and non-jurors' attitudes towards sex offences (Bartels et al., 2014; Warner, 2014). As this article uses data from the first and second stages, the other stages are not discussed here.

\footnotetext{
${ }^{1}$ This project has ethics approval from the University of Tasmania.
} 


\section{Stage 1}

Between 2014 and 2016, we recruited 989 jurors in $128 \operatorname{sex}(N=835)$ and 31 other violent ( $N=154$ ) offence trials involving adult defendants in each of the Australian states and territories except WA (where we were unable to gain the Attorney-General's approval to conduct the study). After the guilty verdict, but before sentence, jurors were asked to select the sentence they thought should be imposed. They were then asked a series of questions about a range of issues, including the purpose of their selected sentence, general views about current sentencing practice, guilty pleas, beliefs about those who commit sex and other violent offences and questions to explore confidence and punitiveness. The paper-based survey (Stage 1) was either completed at the court or taken away and mailed by the juror to the investigators. In South Australia, the surveys were distributed to jurors by mail at the end of each court sitting to comply with the Court's conditions of approval.

There were two comparison groups of non-jurors. Group $1(N=450)$ consisted of members of the public who had responded to the notice to attend for jury service, but were not subsequently selected to serve on a jury ('unempanelled jurors'). If they agreed to participate, they were given a survey which began with a description of one of ten possible vignettes. Nine of these were sex offence scenarios and one was a violent offence.

Group $2(N=306)$ consisted of an online survey of community members. While not part of the original research plan, this was added because we were unable to secure approval from the WA Attorney-General to survey either jurors or unempanelled jurors. The online respondents were recruited through quota sampling of a Qualtrics panel, with participants receiving a small monetary amount from Qualtrics for completion of the survey. The online surveys replicated those used for the unempanelled jurors, with some additional questions. This cohort completed only Stage 1.

\section{Stage 2}

Jurors who indicated in Stage 1 that they would be willing to participate further were invited to complete the Stage 2 survey, which comprised two main sections. The core group of questions in this survey was the same for empanelled and unempanelled jurors. Section A comprised questions on the appropriateness of the sentence, procedural justice and the importance of aggravating and mitigating factors (for jurors, this related to the case they tried, while unempanelled jurors were asked about the case vignette they had received). Section A also included some questions about sex offender registers, which were addressed only to those with a sex offence trial or vignette. Section B repeated some general questions from Stage 1, to gauge stability or otherwise over time in punitiveness, confidence and perceptions of leniency in sentencing. 


\section{Findings}

\section{Stage 1}

\section{Support for SOROS}

In Survey 1, respondents were asked the following question about the offender in their case: 'Should a sex offender registration order (which requires the offender to have reporting obligations to the police and imposes other restrictions) be added to the sentence?'

\section{[insert Table 2 about here]}

As shown in Table 2, most respondents in all three cohorts supported imposing a SORO in their case. There were no significant or meaningful differences between these groups in the overall level of support for a SORO. However, the level of support varied within the groups based on the age of the victim (i.e. child versus adult). ${ }^{2}$ For empanelled jurors, the level of support for a SORO was significantly higher for cases involving child victims $(84 \%)$ compared with adult victims $(65 \%)\left[\chi^{2}(1, N=762)=27.73, p<.001, O R=2.85(95 \%\right.$ OR $=$ $1.91,4.26)]$, although the effect size was small. For unempanelled jurors and the online sample, there were slightly higher levels of support for a SORO in cases involving child victims compared with adult victims, but these differences were not significant or meaningful.

Further to this, the differences between the groups in levels of support for a SORO for cases involving child victims were not significant or meaningful. However, the level of support for a SORO in cases involving adult victims was significantly lower for empanelled jurors compared with unempanelled jurors $\left[\chi^{2}(1, N=286)=7.81, p<.01, O R=2.13(95 \% O R=\right.$ $1.25,3.63)]$ and the online sample $\left[\chi^{2}(1, N=248)=6.63, p=.01, O R=2.17(95 \% O R=1.20\right.$, $3.13)]$. These differences were meaningful, but the effects sizes were small.

\section{Stage 2}

As set out above, the online sample completed only Stage 1 . The 450 unempanelled jurors were invited to complete Stage 2, but only 160 returned a response. The number of empanelled jurors with valid responses at Stage 2 was far fewer once violent cases and cases where a SORO was not mentioned in sentencing remarks were excluded. Accordingly, we have chosen to present only the data from empanelled jurors here. As set out above, the differences across the three cohorts showed few meaningful differences and so we infer that the responses from empanelled jurors are likely to be representive of the total sample. However, we ackowledge that only 385 of the 989 empanelled jurors who participated in Survey 1 proceeded to Survey 2 and questions about SOROs were not applicable for some of these, because they had participated in a non-sexual violent offence trial. These results should

\footnotetext{
${ }^{2}$ Participants from trials/cases involving child exploitation material were excluded from these comparisons, due to the different nature of these crimes and lower number of cases involving this type of crime.
} 
therefore be treated with some caution. Nevertheless, they represent the strongest data available on the public's perspective on SOROs in an actual case where they have detailed information about the case, as opposed to an abstract conception of such orders (cf Taylor 2017).

\section{Appropriateness of Judge's Order in Their Case}

To gauge empanelled jurors' support for the action taken in their case, they were asked: 'If the judge in your case made an order for a sex offender register, how appropriate do you think it was to make this order?' As a matter of sentencing practice, only the sentencing remarks from Victoria and Tasmania include a reference to the SORO. Consequently, only Victorian and Tasmanian jurors from sex offence trials could answer this question. Responses were received from 186 Victorian jurors and 19 Tasmanian jurors creating a combined sample of $N=205$ to explore empanelled jurors' views on appropriateness. There were high levels of support for the judge's decision, with $89 \%$ of respondents indicating this was very appropriate and $9 \%$ stating this was fairly appropriate, compared with $1 \%$ and $<1 \%$ respectively who considered the judge's decision to be fairly or very inappropriate. The Victorian jurors were more likely than those from Tasmania to endorse the 'very appropriate' option (91\% vs $74 \%$ ), although the small number of Tasmanians precluded inferential tests.

\section{Support for Judicial Discretion}

Empanelled jurors were also asked: 'In general how much discretion do you think judges should have in deciding whether or not to place a sex offender on a register?' In cases involving adult victims $(N=311)$, the most common response was 'a little' $(38 \%)$, followed by 'none at all (should be compulsory)' (37\%), while a quarter felt that judicial officers should have 'a great deal' of discretion. As noted above, at present, only three jurisdictions Victoria, Tasmania and Western Australia - currently have scope to include offenders whose victims are adults. Although these findings suggest that expanding the scope of such registers would be popular, the majority of respondents $(63 \%)$ would not favour automatic registration.

In cases involving child victims $(N=323)$, the proportion of respondents who supported 'a great deal' of discretion remained the same $(25 \%)$, but the most common response was 'none at all' (60\%), at the expense of 'a little' discretion (16\%). Accordingly, although one in four respondents supported significant judicial discretion, regardless of the victim's age, this support is much more constrained for most respondents when it comes to child victims. This is much more closely aligned with the current legislative framework.

\section{Support for SORO on the Basis of Sentence Type}

When asked 'In your opinion, which of the following sentences for sexual offences against children, if any, should automatically attract a sex offender registration order?', respondents were almost universal (96\%) in their support for automatic registration in cases resulting in a prison sentence. However, this fell to $61 \%$ for cases resulting in community supervision and 
to around a third for cases resulting in less serious penalties, demonstrating respondents' support for judicial discretion in such cases.

\section{[insert Table 3 about here]}

\section{Access to the Sex Offender Register}

Respondents were asked: 'In your opinion, which of the following groups, if any, should be given access to the sex offender register?' The data set out in Table 4 show broad support for allowing access to parents or carers of children who are mostly likely to be affected by contact with a registered offender, which is generally consistent with the model available in Western Australia, although over a quarter of respondents did not support such access. Importantly, there was relatively little support (35\%) for members of the public generally to have access to this information.

\section{[insert Table 4 about here]}

To better understand respondents' perspectives on this question, we asked for additional information on the types of individuals or organisations that should be allowed to access this information. We received 56 open-text responses (more than one response was possible). By far the most common response was schools and/or childcare centres $(N=23)$, although some included comments such as 'principal and only direct teaching staff of school if, say, one of the parents was on the Register' and 'senior members of institutions involved in activities of groups of children'. The next most common responses were the police $(N=9)$ and community groups, clubs and churches $(N=9)$, followed by hospitals/doctors and employers (both $N=6$ ). Perhaps surprisingly, only two respondents explicitly mentioned victims, one of whom also suggested 'people whose work places them at high risk of becoming a victim e.g. workers who visit people to provide services in their homes'. There was also one response each for a range of other people and organisations that should have access to the information, such as judicial officers, foster carers, co-residents and councils.

Some provided responses such as 'all sorts of sex offenders' and 'background checks on people wanting to work with children should include this information'. One suggested that the offender's '[r] eporting officer should actively manage child sex offenders. Ensure they are not living with vulnerable children or engaging in activities (coaching/school) when they can access children'. However, the responses also suggested a degree of ambivalence about broad access to this information; several suggested that members of the public and parents should not have access, as this 'would result in fear', although another respondent was 'in a quandary: what is the point of a register that nobody sees?'

\section{Discussion}

Support for Sex Offender Registers 
Our analysis shows that there is general support for the use of sex offender registers across all three cohorts, particularly for those convicted of sex offences against children. This finding is consistent with previous research that has identified that 'sexual offences against children are seen as qualitatively different from those against other victims' (Freiberg et al., 2015, p. 138). It is also consistent with US studies that show a high level of community support for sex offender registration policies (Connor, 2020).

The differential level of support for sex offender registers, based on whether the victim was a child or adult, shows a level of nuance in people's views of sex offender registration, depending on the nature of the offence. There appears to be an implicit assumption that sex offences against children are more serious - and the perpetrators therefore more deserving of close monitoring - than offences against adults. This separation is reflected in current Australian sex offender registration legislation, which mostly applies only to offenders with child victims. Although beyond the scope of the present study, future research could consider public attitudes to the registration of juvenile sex offenders.

\section{Judicial Discretion in the Imposition of a SORO}

Among empanelled jurors who participated in the second stage of our survey, there was more support for constraints on judicial discretion in child sex offence cases than in those with an adult victim. This is not surprising, as previous Australian research has shown that jurors in child sexual assault trials are more likely to be dissatisfied with the judge's sentence and are far more likely nominate a more severe sentence than that imposed by the judge than in cases involving rape of an adult or those with consenting teenagers (Tasmanian Sentencing Advisory Council, 2013; Warner et al., 2017).

Our findings on public support for judicial discretion, at least in relation to adult victims, aligns with Simmons' (2019) suggestion that the conditions imposed on registered offenders should be determined by judicial officers, not universally applied. The NSW Law Enforcement Conduct Commission (LECC) recently conducted a review of the Child Protection (Offenders Registration) Act 2000 (NSW). The review identified the 'urgent need for wholesale reform' (2019, p. 126), a conclusion with which the NSW Police reportedly agreed. Significantly, the LECC suggested that 'any law reform process should consider whether judicial officers should be given statutory responsibility for determining whether a person meets the definition of a registrable person, and calculating their initial reporting period' (2019, p. 127). The LECC noted that, although Parliament did not intend for judicial officers to have a role in deciding whether someone was a registrable person under the NSW Act, it emerged that applying the provisions was not straightforward and often 'required the consideration of a significant amount of information and the exercise of judgement, and could not merely "flow automatically from a finding of guilt" (2019, p. 136).

The LECC also found that police had incorrectly determined that 96 people were not registrable when they in fact were and that 43 people were registerable when they should not have been. The LECC determined that the NSW Police had unlawfully required offenders to 
report their personal details for a number of years and erroneously charged and arrested people for purported misconduct. In fact, an internal review of 5,749 case files revealed errors in $49 \%$ of the reviewed files (LECC, 2019). A recent review of the Victorian scheme also found that the information system used introduced the potential for mistakes (Victorian Auditor-General's Office (VAGO), 2019). This experience is not unique to Australia, with the Vermont Auditor-General (2014) finding a considerable number of errors in its comparable regime, calling into question the reliability of the register there.

\section{The Impact of Sentence Type on Support for SORO}

Respondents were most likely to support automatic imposition of a SORO when it was attached to a sentence of imprisonment. However, as the severity of the sentence decreased, so did support for automatic registration, with only a third of respondents supporting this where the sentence was a fine, good behaviour bond or no conviction recorded. This indicates that the public response is more nuanced than might generally be assumed.

As set out in Table 1, five out of eight jurisdictions provide an exception to the mandatory registration requirement on the basis of sentence type, although this is generally rather limited in its scope. Our findings demonstrate clear nuance in the responses on this issue, suggesting that there may be public support for further differentiation in the application of the various Australian schemes, based on the sentence imposed. Implicitly, this finding also supports judicial discretion in sentencing more generally, given that respondents appeared to recognise that different cases will yield different sentencing outcomes, based on a range of factors relating to the offence and offender.

\section{Access to Sex Offender Registers}

In the context of current moves towards establishing a national public child sex offender register in Australia, the question of public access to such information becomes critical. The Law Council of Australia has expressed concern about the Federal Government's proposal, noting the need for balance between protecting the community and protecting the basic rights and liberties of released offenders who have already been sentenced. It also argued that the 'courts must play a role in supervising the exercise of these powers' (2019, p. 5), including judicial determination of who is placed on the public register. Our findings suggest such a move would likely be supported by the public.

Our findings show that only one-third of respondents support general public access to information on a sex offender register, while three-quarters support access by the government or carers of a child who has contact with an offender. It seems, then, that people appreciate the potential problems with allowing open access on register information to the general public. In addition, more than one in four respondents did not think even parents or carers should have access to this information. Further research is required to understand the basis for such objections (eg, privacy, concerns about vigilante justice, belief in offenders' redeemability). 
Commenting on the Federal Government's proposal to introduce a public register, Harris suggested that 'the 20-year legislative experiment in the US has been an abject failure' (2019, $\mathrm{np}$ ). Significantly, she asserted that the US model had 'left prisons overcrowded, families devastated, victims publicly identified, survivors re-traumatised, and communities fractured' $(2019, \mathrm{np})$. She also observed that there are people on the register who should not be and people who should be on the register, but are not. The recent findings by the LECC (2019) in NSW bear this out and should also be noted in this context.

\section{Conclusion}

The principal benefit of SORN laws appears to be as an communication and investigative tool for law enforcement, although there is some limited evidence of reduced numbers of sex offences (see eg Cui et al. 2018). However, there have also been numerous criticisms of the operation and efficacy of such laws (see eg Vess et al., 2011; Napier et al., 2018), with Simmons describing the aims of the Victorian model as 'misguided' and unlikely to reduce sexual violence (2019, p. 791). Recent reviews by the VAGO (2019) and LECC (2019) in NSW have highlighted some concerns about their operation, although restrictions imposed on access to the registers (see eg, s 63 of the Sex Offenders Registration Act 2004 (Vic)) mean there is generally little information on this issue. It should be noted that the number of people subject to such orders is not trivial; as of May 2019, there were 8,286 registered sex offenders in Victoria alone (VAGO, 2019).

One of the main obstacles to the effectiveness of public sex offender registers and community notification schemes in general is that the vast majority of sexual offences are committed by people whom the victim knows: $83 \%$ of child sexual assault victims are assaulted by someone they know and only $10 \%$ of child victims are assaulted by a stranger (the nature of the relationship was unknown in the remaining cases) (Napier et al., 2018). This means that public sex offender register schemes on their own are unlikely to be ineffective in protecting the community. Accordingly, such registers represent only part of the response to sex offending, which needs to be considered in conjunction with other methods for reducing recidivism (Napier et al., 2018). Furthermore, as Harris (2019) has noted, law enforcement resources are finite and should be focused on detecting, investigating and apprehending active criminals, rather than monitoring tens of thousands of people, many of whom have been 'wrongly identified, or with decades-old convictions for isolated offences'. This is supported by the recent finding in Victoria that some compliance managers are required to supervise almost 100 registered sex offenders, with high workload demands meaning that some registered offenders receive less management, regardless of their risk level (VAGO, 2019).

It is debateable not only whether these measures will be effective in reducing reoffending, but whether they are aligned with actual, as opposed to presumed, public sentiment. Our findings provide the most comprehensive analysis of public opinion in Australia on this issue. They indicate general support for use of sex offender registers, with limited judicial discretion. However, this support is nuanced, as it depends on both the type of offence and the type of 
sentence imposed. Accordingly, jurisdictions should consider expanding both the legislative exceptions to automatic registration in circumstances where a non-custodial order is imposed and the role of judicial officers in determining when an order is appropriate (as is the case in Tasmania) and the operation of the regime itself.

Our findings also indicate that there is little support for the register to be made publicly available, with only one third of participants in favour. Taken together with the evidence on the lack of effectiveness of public sex offender registers, this reinforces criticisms of the proposal to introduce a national public register in Australia (see eg Conifer, 2019; Harris, 2019; Law Council of Australia, 2019; Sakzewski, 2019). The concept of 'crime control theatre' refers to policies that appear to address crime, but which may be ineffective and potentially have unintended negative consequences (de Vault et al., 2016). The Australian Government's proposal to introduce a public sex offender register should be recognised as a form of such theatre and is unlikely to be popular with an Australian audience.

\section{Acknowledgements}

This study would not have been possible without the generous support of state and territory courts, judges and Attorneys-General. We gratefully acknowledge their willingness to participate in this research by granting us access to their jury pool members or otherwise assisting us with undertaking this work. Special thanks are due to the Victorian Juries Commissioner and his staff, who enthusiastically and wholeheartedly supported our work and to Rachel Vermey for her help with data analysis and Rebecca Bradfield for comments on the draft.

\section{Funding}

The authors disclosed receipt of the following financial support for the research, authorship and/or publication of this article: The project was funded by an Australian Research Council Linkage Grant, Project ID: LP 130100083 with the following partners: Department of Justice, Tasmania; VSAC; Australasian Institute of Judicial Administration; and the ACT Victims of Crime Commissioner.

\section{References}

Australian Criminal Intelligence Commission (2020). Protection services. Retrieved from https://www.acic.gov.au/our-services/protection-services\#accordion-2

Australian Government (2019). Budget 2019-20: Budget measures budget paper no 2. Canberra: Commonwealth of Australia.

Bartels, L., Walvisch, J., \& Richards, K. (2019). More, longer, tougher...or is it finally time for a different approach to the post-sentence management of sex offenders in Australia? Criminal Law Journal, 43(1), 41-57. 
Bartels, L., Warner, K., \& Zdenkowski, G. (2014). National research with jurors on sentences for sexual offenders, Judicial Officers' Bulletin, 26(2), 9-12.

Conifer, D. (2019). Peter Dutton proposes public register of child sex offenders. ABC News, 9 January. Retrieved from https://www.abc.net.au/news/2019-01-09/peter-duttonproposes-national-database-of-sex-offenders/10701202

Connor, D. (2020). Impressions of ineffectiveness: Exploring support partners' attitudes toward sex offender registration and notification. Psychology, Crime \& Law, 26(2), 128-147. https://doi.org/10.1080/1068316X.2019.1634199

Cubellis, M., Walfield, S., \& Harris, A. (2018). Collateral consequences and effectiveness of sex offender registration and notification. International Journal of Offender Therapy and Comparative Criminology, 62(4), 1080-1106. https://doi.org/10.1177/0306624X16667574

Cui, L., Fairfax, M., Chand, P., Singh, S., \& Sheldon, G. (2018). The benefits and detriments of sex offender registers. Macquarie University.

Day. A., Carson, E., Newton, D., \& Hobbs, G. (2014). Professional views on the management of sex offenders in the community. Journal of Offender Rehabilitation, 53(3), 171189. https://doi.org/10.1080/10509674.2014.887605

deVault, A., Miller, M. K., \& Griffin, T. (2016). Crime control theater: Past, present, and future. Psychology, Public Policy, and Law, 22(4), 341-348. https://doi.org/10.1037/law0000099

Freeman, N. (2012). The public safety impact of community notification laws: Rearrest of convicted sex offenders. Crime and Delinquency, 58(4), 539-564. https://doi.org/10.1177/0011128708330852

Freiberg, A., Donnelly, H., \& Gelb, K. (2015). Sentencing for child sexual abuse in institutional contexts. Sydney: Royal Commission into Institutional Responses to Child Sexual Abuse.

Gately, N., \& Carpenter, T. (2019). 'WA's public sex offender registry: It's our right to know - oh but we don't use it!'. Paper presented at the Australian and New Zealand Society of Criminology Conference, Perth, December. Retrieved from http://anzsocconference.com.au/4545

Hall, M. (2019). Sex offender registries don't prevent re-offending (and vigilante justice is real), The Conversation, 10 January. Retrieved from https://theconversation.com/sexoffender-registries-dont-prevent-re-offending-and-vigilante-justice-is-real-109573

Harris, A., Levenson, J., Lobanov-Rostovsky, C., \& Walfield, S. (2018). Law enforcement perspectives on sex offender registration and notification: Effectiveness, challenges, and policy priorities. Criminal Justice Policy Review, 29(4), 391-420. https://doi.org/10.1177/0887403416651671

Harris, A., Lobanov-Rostovsky, C., \& Levenson, J. (2010). Widening the net: The effects of transitioning to the Adam Walsh Act's federally mandated sex offender classification 
system. Criminal Justice and Behavior, 37(5), 503-519.

https://doi.org/10.1177/0093854810363889

Harris, D. (2019). Why Australia should not have a public register of child sex offenders. Sydney Morning Herald, 9 January. Retrieved from https://www.smh.com.au/national/why-australia-should-not-have-a-public-register-ofchild-sex-offenders-20190109-p50qcy.html

Harris, D., \& McPhedran, S. (2018). The sentencing and supervision of individuals convicted of sexual offences in Australia. Sexual Offender Treatment, 13(1/2). Retrieved from http://www.sexual-offender-treatment.org/167.html

Kim, H-K (2019). Community notification of sex offenders against children in South Korea: Current laws and policies. Paper presentated at the Stockholm Criminogy Symposium. Retrieved from https://www.criminologysymposium.com/download/18.62c6cfa2166eca5d70e2d6f2/1 561723095865/MON12 KIM_HAN_KYUN.pdf

Law Council of Australia (2019). Letter on National Public Register of Child Sex Offenders, 11 January. Retrieved from https://www.lawcouncil.asn.au/docs/ad51022d-c355e911-93fc-005056be13b5/3566\%20\%20National $\% 20$ Sex $\% 20$ Offender $\% 20$ Register.pdf

Layt, S. (2019). Child protection advocate labels sex offender register a "waste of money". Brisbane Times, 7 April. Retrieved from https://www.brisbanetimes.com.au/national/queensland/national-child-sex-offendersregister-is-a-waste-of-money-20190404-p51ayr.html

Letourneau, E., Levenson, J., Bandyopadhyay, D., Sinha, D., \& Armstrong, K. (2010). Effects of South Carolina's sex offender registration and notification policy on adult recidivism. Criminal Justice Policy Review, 21(4), 435-458. https://doi.org/10.1177/0887403409353148

Malsa, M. (2020). Child sex offenders registry not up to date. The Edition, 19 January. Retrieved from https://edition.mv/news/14523

Masters, K., \& Kebbell, M. (2019). Police officers' perceptions of a sex offender registration scheme: Identifying and responding to risk. Psychiatry, Psychology and Law, 26(3), 396-413. https://doi.org/10.1080/13218719.2018.1506717

McKay, C. (2020). Predicting risk in criminal procedure: actuarial tools, algorithms, AI and judicial decision-making. Current Issues in Criminal Justice, 32(1), 22-39, DOI: $10.1080 / 10345329.2019 .1658694$

Napier, S., Dowling, C., Morgan, A., \& Talbot, D. (2018). What impact do public sex offender registries have on community safety? Canberra: Australian Institute of Criminology.

NSW Law Enforcement Conduct Commission (2019). The New South Wales child protection register: Operation Tusket final report. Sydney. 
Powell, M., Day, A., Benson, M., Vess, J., \& Graffam, J. (2014). Australian police officers' perceptions of sex offender registries. Policing and Society: An International Journal of Research and Policy, 24(1), 120-133.

https://doi.org/10.1080/10439463.2013.784299

Prescott, J. \& Rockoff, J. (2011). Do sex offender registration and notification laws affect criminal behavior? Journal of Law \& Economics, 54(1), 161-206.

Sakzewski, E. (2019). Peter Dutton wants a national child sex offenders registry. But do they actually work? $A B C$ News, 9 January. Available at https://www.abc.net.au/news/2019-01-09/how-duttons-national-child-sex-offendersregistry-will-work/10701382

Seidler, K. (2010). Community management of sex offenders: Stigma versus support. Sexual Abuse in Australia and New Zealand: An Interdisciplinary Journal, 2(2), 66-76.

Shackley, M., Weiner, C., Day, A., \& Willis, G. (2014). Assessment of public attitudes towards sex offenders in an Australian population. Psychology, Crime \& Law, 20(6), 553-572. https://doi.org/10.1080/1068316X.2013.793772

Simmons, M. (2019). Evaluating the legal assumptions of Victoria's Sex Offender Registration Act 2004 from a psychological perspective. Psychiatry, Psychology and Law, 26(5), 783-796. https://doi.org/10.1080/13218719.2019.1642254

Tasmania Sentencing Advisory Council (2013). Sex offence sentencing: Research paper. Hobart.

Taylor, S. (2017). Community perceptions of a public sex offender registry introduced in Western Australia. Police Practice and Research, 18(3), 275-290. https://doi.org/10.1080/15614263.2017.1291572

Vermont State Auditor (2014). Sex offender registry: Questionable reliability warrants additional improvements. Montpelier.

Vess, J., Langskaill, B., Day, A., Powell, M., \& Graffam, J. (2011). A comparative analysis of Australian sex offender legislation for sex offender registries. Australian and New Zealand Journal of Criminology, 43(3), 404-424. https://doi.org/10.1177/0004865811419065

Victorian Auditor-General's Office (2019). Managing registered sex offenders. Melbourne.

Vitis, L. (2018). Vagaries, anxieties and the imagined paedophile: A Victorian case study on mandatory sex offender registration for young adult registrants convicted after nonconsensually distributing intimate images. International Journal for Crime, Justice and Social Democracy, 7(4), 115-131. https://doi.org/10.5204/ijcjsd.v7i4.1084

Warner, K. (2014). The Australian national jury sex offence sentencing study. The Judicial Review, 11(4), 459-480.

Warner, K., \& Davis, J. (2012). Using jurors to explore public attitudes to sentencing. British Journal of Criminology, 52(1), 93-112. https://doi.org/10.1093/bjc/azr066 
Warner, K., Davis, J., Spiranovic, C., Cockburn, H., \& Freiberg, A. (2017). Measuring jurors' views on sentencing: Results from the second Australian jury sentencing study. Punishment \& Society, 19(2), 180-202.

https://doi.org/10.1177/1462474516660697

Whitting, L., Day, A., \& Powell, M. (2017). An evaluation of the impact of Australia's first community notification scheme. Psychiatry, Psychology and Law, 24(3), 339-355. https://doi.org/10.1080/13218719.2016.1247606

Whitting. L., Day, A., \& Powell, M. (2016). Police officer perspectives on the implementation of a sex offender community notification scheme. International Journal of Police Science \& Management, 18(4), 261-272.

https://doi.org/10.1177/1461355716668539 
Table 1: Legislative Framework for Australian SOROs

\begin{tabular}{|l|l|l|l|}
\hline Jdn & Legislation & $\begin{array}{l}\text { Registrable } \\
\text { offender }\end{array}$ & $\begin{array}{l}\text { Exception for certain } \\
\text { sentencing outcomes }\end{array}$ \\
\hline ACT & Crimes (Child Sex Offenders) Act 2005 & s 8 & ss 9(1)(a), (b) \\
\hline NSW & $\begin{array}{l}\text { Child Protection (Offenders Registration) Act } \\
2000\end{array}$ & s 3A & s 3A(2)(a) \\
\hline NT & $\begin{array}{l}\text { Child Protection (Offender Reporting and } \\
\text { Registration) Act 2004 }\end{array}$ & s 6(1) & ss 11(1)(b), (c) \\
\hline QId & $\begin{array}{l}\text { Child Protection (Offender Reporting and } \\
\text { Child Sex Offenders Registration Act 2006 }\end{array}$ & s 5(1) & ss 5(2)(a), (b) \\
\hline Tas & $\begin{array}{l}\text { Community Protection (Offender Reporting) Act } \\
\text { 2005 }\end{array}$ & ss 5, 6 & s 6(3)(b) \\
\hline Vic & $\begin{array}{l}\text { Sex Offenders Registration Act 2004 } \\
\text { Community Protection (Offender Reporting) Act }\end{array}$ & s 6(1) & \\
\hline WA & so04 6 & \\
\hline
\end{tabular}

Table 2: Support for SOROs, by Cohort and Victim Age

\begin{tabular}{|l|c|c|c|c|c|c|}
\hline & \multicolumn{2}{|c|}{ Empanelled jurors } & \multicolumn{2}{c|}{ Unempanelled jurors } & \multicolumn{2}{c|}{ Online sample } \\
\hline & $\mathrm{N}$ & $\%$ & $\mathrm{~N}$ & $\%$ & $\mathrm{~N}$ & $\%$ \\
\hline $\begin{array}{l}\text { Support for SORO - child } \\
\text { victim }\end{array}$ & 614 & $84 \%$ & 245 & $87 \%$ & 158 & $81 \%$ \\
\hline $\begin{array}{l}\text { Support for SORO - adult } \\
\text { victim }\end{array}$ & 148 & $65 \%$ & 138 & $80 \%$ & 100 & $80 \%$ \\
\hline Overall support for SORO & 813 & $77 \%$ & 403 & $81 \%$ & 272 & $78 \%$ \\
\hline
\end{tabular}

Table 3: Support for Automatic SORO, by Sentence Type

\begin{tabular}{|l|c|c|c|}
\hline & N & Yes & No \\
\hline Prison & 338 & $96 \%$ & $4 \%$ \\
\hline Community supervision & 337 & $61 \%$ & $39 \%$ \\
\hline Fine or good behaviour bond & 337 & $34 \%$ & $66 \%$ \\
\hline No conviction recorded & 336 & $33 \%$ & $67 \%$ \\
\hline
\end{tabular}

Table 4: Support for Who Should Have Access to Sex Offender Register

\begin{tabular}{|l|c|c|c|}
\hline & $\mathbf{N}$ & Yes & No \\
\hline $\begin{array}{l}\text { Parents or carers of a child who has contact with a } \\
\text { registered sex offender }\end{array}$ & 337 & $73 \%$ & $27 \%$ \\
\hline Government departments & 337 & $74 \%$ & $26 \%$ \\
\hline All members of the general public & 337 & $35 \%$ & $65 \%$ \\
\hline Other & 332 & $12 \%$ & $88 \%$ \\
\hline
\end{tabular}

